\title{
Evaluation of the Results of Diaphyseal Fracture of Femur (Winquist Type II, III and IV) Treated by Open Antegrade Sign Nailing \\ Halder $\mathrm{J}^{*}$, Islam $\mathrm{R}^{2}$, Hasan $\mathrm{MS}^{3}$, Banik $\mathrm{DC}^{4}$
}

\author{
${ }^{1}$ Jibananda Halder, Assistant professor, Department of Orthopaedic Surgery, National Institute of Traumatology and Orthopaedic \\ Rehabilitation (NITOR), Dhaka, Bangladesh \\ ${ }^{2}$ Md Rafiqul Islam, Assistant Professor, Department of Orthopaedic Surgery, Sheikh Hasina Medical College, Jamalpur, Bangladesh \\ ${ }^{3}$ Mir Shahidul Hasan, UHFPO, Dumki Upozila Health Complex, Patuakhali, Bangladesh \\ ${ }^{4}$ Diponkar Chandra Banik, Assistant Register, Department of Orthopaedic Surgery, (NITOR), Dhaka, Bangladesh
}

DOI: $10.36347 /$ sasjs.2021.v07i01.001

| Received: 16.12.2020 | Accepted: 31.12.2020 | Published: 08.01.2021

*Corresponding author: Halder J

Abstract

Original Research Article

Introduction: Fracture femur shaft most commonly occurs as a result of high velocity trauma. In the past, these fractures have been treated by various techniques like traction and conservative methods, operative methods like plating, intramedulary nailing. With the advent of Interlocking sign nailing involving diaphyseal fracture of femur in adult have resulted in far better outcomes. The poor patients in our country, who have no assets, suffer the most. The Surgical Implant Generation Network (SIGN) was established in January, 1999 as a humanitarian, nonprofitable organization in the state of Washinton, USA, to provide free of cost and one of the best treatments for long bone fracture in developing country. To find out the result in the treatment of closed diaphyseal fracture of femur (Winquist Type II,III, IV) in adult by open antegrade interlocking SIGN nailing at NITOR. This was a close observational study conducted at the National Institute of Traumatology and Orthopaedic Rehabilitation (NITOR), Dhaka, Bangladesh. Forty five patients with closed diaphyseal fracture (winquist type II, III \& IV) of femur who attended emergency and out patient department and admitted to NITOR from Jan 2018 to Dec 2019. Mean age of the patients was 36.20 years and majority of patients $(93.30 \%)$ were male, with male female ratio of 13:1. In most of the cases, injury was highenergy trauma $(91.1 \%)$ due to road traffic accident, and there was preponderance of fracture on the right side $(35.0 \%)$. All the patients reported early after trauma and majority of the patients $(66.6 \%)$ were operated within 4 weeks. Patients were followed-up postoperatively up to 12 months. All the fractures were fixed by interlocking intramedullary SIGN nail in open procedure. But 4 patients required dynamization and result was delayed union. 1 patient had wound infection before definitive surgery and controlled with Amikacine. At the end of follow-up functional scoring was done on the basis of score cited by Thoresen [1] and the results were excellent in $60 \%$ cases, good $28.90 \%$, fair $11.10 \%$. All achieved union and no evidence of implant failure was seen. $88.9 \%(60 \%+28.90 \%)$ patients result wear satisfactory. Intramedullary nailing (SIGN) has given satisfactory results in my study.

Keywords: Diaphyseal, fracture of femur, SIGN nail, Good method of fixation.

Copyright $\odot 2021$ The Author(s): This is an open-access article distributed under the terms of the Creative Commons Attribution 4.0 International License (CC BY-NC 4.0) which permits unrestricted use, distribution, and reproduction in any medium for non-commercial use provided the original author and source are credited.

\section{INTRODUCTION}

Trauma is a growing global public health concern and it is a major cause of death and disability worldwide. Trauma is the leading cause of death globally among people between the ages of five to forty-five years. Accidents involving motor vehicles are the main cause of musculoskeletal trauma. Femoral fractures are the most common musculoskeletal injury, accounting for $9 \%$ of all injuries [2]. Most fractures of the shaft of the femur are described by the location and geometry of the fracture, the degree of comminution, the severity of the -soft-tissue injury, and the presence or absence of associated injuries. The AO classification and coding system defines twenty-seven distinct patterns of fractures of the femoral shaft. These distinctions are based on the fracture's location proximal, mid-shaft, or distal, anatomy and degree of comminution [3]. SIGN intramedullary nails and screws are designed to provide fixation of femoral and tibial fractures. SIGN nails for both retrograde and antegrade nailing of femur are available. The SIGN intramedullary nail is indicated for internal fixation of diaphyseal femur fractures including transverse fractures, oblique and spiral fractures, comminuted fractures, fractures with bone loss, open fracture, corrective osteotomies, pathological fractures, nonunion and malunion [4]. 


\section{METHODOLOGY \& MATERIALS}

Close observational prospective study that was carried out at National Institute of Traumatology and Orthopaedic Rehabilitation (NITOR), Dhaka, Bangladesh. All operations were done under spinal anaesthesia. Patients were placed in a lateral position and affected side was above. After the patient was anaesthesized, the skin was washed, cleaned with soap and water, dried, and then painted with $10 \%$ povidone iodine solution from umbilicus to bellow knee. Then the patient was draped with sterile sheets exposing only the lateral aspect of the thigh and pyriform fossa. ReamingBoth proximal and distal fragment was reamed through the awl opening and fracture side accordingly with appropriate size of reamer. Progressively reaming was done in $1 \mathrm{~mm}$ increasing to diameter of the nail. It should be mentioned that reaming material was collected through a kidney dish to apply in fracture side. Reduction of fracture was done with manual traction. Incision begins about $3 \mathrm{~cm}$ distal to the greater trochanter and extends proximally in line with the gluteus medius muscle fibers. Antigrade nailing process.

\section{Inclusion Criteria}

a) Patients with diaphyseal fracture of femur.

b. Fresh injuries and less than three weeks of old fractures.

c) Closed fractures d) Adult patients (15-60).

e) Sex - both sexes. f) Trauma of any severity or any kind

Exclusion Criteria

a) Open fracture.

b) Fractures without epiphyseal fusion.

c) Pathological fracture.

d) Patient unfit for major surgical intervention.

e) Fracture nonunion.

f) Patients with bilateral femoral fractures.

g) Patient with deformity of at least one lower limb i.e., Polio, Joint contractures and amputees. h) Patient with underlying uncontrolled co morbid condition i.e., Diabetes mellitus, hypertension.

\section{RESULT}

\section{Postoperative Management}

Postoperatively limb was elevated on a pillow keeping the knee in slight flexion. The patient started isometric quadriceps exercise after 24 hours of operation. After 48 hours, drain was removed. The patient was allowed to move out of bed when patient felt comfort, having crutches and without bearing weight on the operated limb. Stitches were removed on the $10^{\text {th }}$ postoperative day. Knee range of motion exercises were started as early as possible when patients feel comfort. Postoperatively, prophylactic antibiotics were given routinely for 2 weeks in all cases. Patient was discharged with the advice to walk on crutch bearing no weight on the affected side for 6 weeks and then to report to the opd.

\section{Case Report-1}

\begin{tabular}{|l|l|l|l|l|}
\hline Preoperative & F/U after 18 wks & F/U after 36 wks & F/U after 48 wks & $\begin{array}{l}\text { Final F/U full } \\
\text { squatting with smile }\end{array}$ \\
\hline & & &
\end{tabular}

Case Report-2

\begin{tabular}{|l|l|l|l|l|}
\hline Pre-Operative & F/U after 10 wks & F/U after36 wks & F/U After 1 yr & $\begin{array}{l}\text { Final F/U full } \\
\text { squatting with smile }\end{array}$ \\
\hline & & & &
\end{tabular}


Observation and Results: Functional outcome:

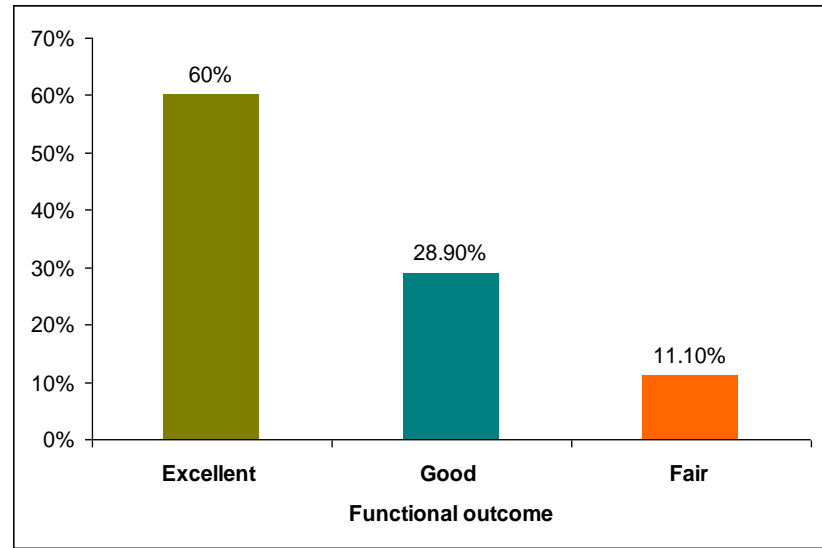

Distribution of patients by functional outcome Final follow up result: shows that the satisfactory result (excellent + good) was $40(88.9 \%)$ and unsatisfactory (fair) 5(11.1\%).

\section{DISCUSSION}

Fractures of the femoral shaft, remains as a therapeutic challenge. In the present series, the age of the patients varied from minimum 15 years to maximum 60 years, mean age being 36.20 years. Near findings were also been noted where the average age of the patients were 31-40 years, respectively in the study of Thoresen [1] and Brumback et al., [5]. The incidence of male female ratio of this series is 13:1 and the series of Brumback et al., [6] was 4: 1. Regarding the nature of trauma it was found that majority amount of shaft fracture $(91.1 \%)$ occurred due to high-energy trauma, in which $66.7 \%$ was due to automobile accidents. Only $8.9 \%$ of femoral shaft fractures occurred due to lowenergy trauma. In the series of Thoresen [1], highvelocity trauma accounted for $77 \%$ of the femoral shaft fractures. Interlocking intramedullary SIGN nailing is valuable option especially in diaphyseal fracture of the femoral shaft as it helps in controlling rotation [7]. But this series had few problems of malalignment as those reported by others. Up to $10^{0}$ of varus deformities in 2 cases was observed in the series of Kempf et al., [8], but no rotational deformity. Christie et al., did not find any malunion in their series, except in one case where there was $15^{0}$ lateral rotation deformities. In this series, 5 patient developed varus deformity of up to $10^{\circ}$ and valgus upto $5^{\circ}$. The experience regarding this series was very minimum and the follow-up period was also very short as compared to the above mentioned series, though the problem of malalignments were not as much as in series of Thoresen [1] where 2 patients have genurecurvaturn up to $15^{\circ}$ and a patient with $40^{\circ}$ external rotation deformity. $2 \%$ malalignment was found in the study of Ricci et al., [9] and average 4.8 degree angular deformity was noted in the study of Okcu G and Aktuglu K [10]. 88.90\% of the fractures were united in this series within expectation and were capable of full weight bearing, The fracture union was

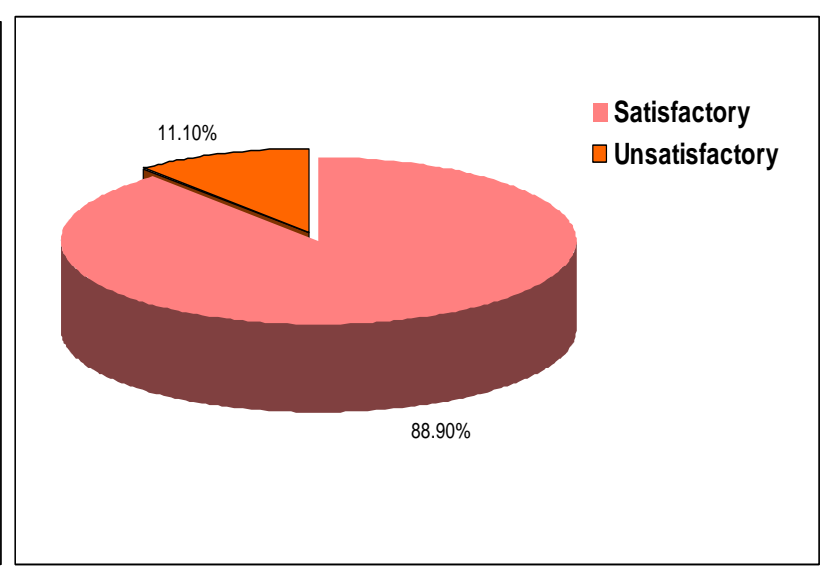

defined as the period between injury and weight bearing. Roentgenographically healed fracture was characterized by cortical bridging in two views.

Delayed union occurred in $5(11.9 \%)$ patients. Before 16 weeks satisfactory bridging was not seen in the fracture line. These 5 patients were ultimately united after dynamization. But these 5 patients had mild to moderate limitations in their routine activities. In final follow-up, the satisfactory result (excellent and good) of this was $88.9 \%$. Satisfactory result of Kempf et al., [11] was $90.4 \%$ and of Thoresen et al., [1] was $93.8 \%$. By comparison of the results of this series with the results of previous interlocking nail fixation for femur done in NITOR by Dr. Faruq Quasem 2000 [12] for distal third femoral fracture by retrograde interlocking nailing with Sign nail and satisfactory result was $76.66 \%$. So the result of study of current series is satisfactory in respect to previous published study.

\section{Limitations of the Study}

This was a single centered study with small size sample. So, study results may not be reflect the exact scenario of the whole country.

\section{CONCLUSION AND RECOMMENDATIONS}

Our meta-analysis did not confirm superiority of either antegrade over retrograde nailing, or trochanteric over piriformis entry in IM nailing of the femur. The 2 included studies varied in quality and outcomes reported and thus higher-quality studies are required to clearly establish any recommendations. We suggest that surgeons use their best judgment as to the choice of entry point based on surgeon comfort with the technique and on patient and fracture characteristics.

Funding: No funding sources.

Conflict of interest: None declared.

\section{REFERENCES}

1. Thoresen BO, Alho A, Ekeland A, Strømsøe K, Follerås G, Haukeb $\emptyset \quad$ A. Interlocking 
intramedullary nailing in femoral shaft fractures. A report of forty-eight cases. JBJS. 1985 Dec 1;67(9):1313-20.

2. Sekimpi P, Okike K, Zirkle L, Jawa A. Femoral fracture fixation in developing countries: an evaluation of the Surgical Implant Generation Network (SIGN) intramedullary nail. JBJS. 2011 Oct 5;93(19):1811-8.

3. Bucholz RW, Jones A. Current concepts review fractures of the shaft of the femur. Journal of Bone and Joint Surg (Am), 1991; 73(10):1561-6.

4. Zirkle M, Blum R, Raemer DB, Healy G, Roberson DW. Teaching emergency airway management using medical simulation: a pilot program. The Laryngoscope. 2005 Mar;115(3):495-500.

5. Brumback RJ, Reilly JP, Poka A. Intramedullary nailing of femoral shaft fractures, Journal of Bone and Joint Surg Am. 1988; 70(10):1441-52.

6. Brumback RJ, Ellison TS, Poka A, Bathon GH, Burgess AR. Intramedullary nailing femoral shaft fractures. Journal of Bone and Joint Surg (Arm), 1992; 74:106-12.

7. Pati BN, Bansal VP, Krishna LG, Ahmed A, Garg S. Interlocking nail of femur. A review of 90 classes. Ind J Orthop. 2001;35(1):49-51.
8. Kempf W, Pfaltz K, Vermeer MH, Cozzio A, Ortiz-Romero PL, Bagot M, Olsen E, Kim YH, Dummer R, Pimpinelli N, Whittaker S. EORTC, ISCL, and USCLC consensus recommendations for the treatment of primary cutaneous CD30positive lymphoproliferative disorders: lymphomatoid papulosis and primary cutaneous anaplastic large-cell lymphoma. Blood, The Journal of the American Society of Hematology. 2011 Oct 13;118(15):4024-35.

9. Ricci F, Werthner H. Case base querying for travel planning recommendation. Information Technology \& Tourism. 2001 Mar 1;4(3-4):21526.

10. Okcu G, Aktuglu K. Antegrade nailing of femoral shaft fractures combined with neck or distal femur fractures. Archives of orthopaedic and trauma surgery. 2003 Dec 1;123(10):544-50.

11. Kempf I, Grosse A, Beck G. Closed locked intramedullary nailing. Its application to comminuted fractures of the femur. JBJS. 1985 Jun 1;67(5):709-20.

12. Al Faruq A. Understanding SE Growth: The Case of Bangladesh (Doctoral dissertation, Middlesex University). 